\title{
Assessment of Long-term Groundwater Use Increase and Forest Growth Impact on Watershed Hydrology
}

\section{Wonjin Kim}

Konkuk University https://orcid.org/0000-0002-2302-3999

Seongjoon Kim ( $\nabla$ kimsj@konkuk.ac.kr)

Konkuk University - Seoul Campus: Konkuk University https://orcid.org/0000-0002-9729-9373

Jinuk Kim

Konkuk University - Seoul Campus: Konkuk University

Jiwan Lee

Konkuk University - Seoul Campus: Konkuk University

\section{Soyoung Woo}

Konkuk University - Seoul Campus: Konkuk University

\section{Sehoon Kim}

Konkuk University - Seoul Campus: Konkuk University

\section{Research Article}

Keywords: Stream drying phenomena, Groundwater use increase, Forest growth, SWAT

Posted Date: November 1st, 2021

DOI: https://doi.org/10.21203/rs.3.rs-791384/v1

License: (1) This work is licensed under a Creative Commons Attribution 4.0 International License. Read Full License 
1 Assessment of Long-term Groundwater Use Increase and Forest Growth Impact on

2 Watershed Hydrology

3

4 Running head: Long-term Groundwater Use Increase and Forest Growth Impact

5

6 Wonjin Kim ${ }^{1}$, Seongjoon Kim ${ }^{2}$, Jinuk Kim ${ }^{1}$, Jiwan Lee ${ }^{1}$, Soyoung Woo ${ }^{1}$, Sehoon Kim ${ }^{1}$

$7{ }^{1}$ Department of Civil, Environmental and Plant Engineering, Graduate School, Konkuk

8 University, Seoul 05029, South Korea

92 Division of Civil and Environmental Engineering, College of Engineering, Konkuk 10 University, Seoul 05029, South Korea

12 Corresponding Author

13 Name: Seongjoon Kim

14 Mailing Address: Room \#237, D-dong, College of Engineering, Konkuk University,

15 Neungdongro 120, Seoul, South Korea

16 Email address: kimsj@konkuk.ac.kr 
Abstract

This study used Soil and Water Assessment Tool (SWAT) to investigate the impacts of groundwater use increase and forest growth on the watershed hydrology of Geum River basin $\left(9,645.5 \mathrm{~km}^{2}\right)$, South Korea. Groundwater use increase and forest growth data from 1976 to 2015 were prepared in 10-year interval and were reflected to SWAT corresponding to each decade. SWAT was calibrated in the aspect of evapotranspiration, soil moisture, and streamflow using the observation data. The model performance for streamflow was evaluated by coefficient of determination $\left(\mathrm{R}^{2}\right)$, Nash-Sutcliffe efficiency (NSE), root mean square error (RMSE), and percent bias (PBIAS). The calibration achieved the average $\mathrm{R}^{2}$ value of $0.73 \sim 0.82$, NSE value of $0.75 \sim 0.81$, RMSE value of $0.53 \sim 2.35 \mathrm{~mm} /$ day, and PBIAS value of $-2.51 \sim+11.74 \%$, respectively. The model performance for evapotranspiration and soil moisture was evaluated by $\mathrm{R}^{2}$. The calibration result of evapotranspiration and soil moisture achieved average $\mathrm{R}^{2}$ value of 0.45 and 0.44 , respectively. The calibrated model evaluated the impact of two factors on watershed hydrology. Decadal increase of groundwater use has decreased groundwater flow and increased groundwater recharge while decadal forest growth has mainly increased evapotranspiration that led to the decrease of other hydrological components. Resultingly, the change of two factors have imposed temporal decrease of total runoff on the watershed while the influence of two factors on annual streamflow loss was bigger in lower flow rate. 


\section{INTRODUCTION}

Stream drying phenomena, which are often defined as long-term declines in water levels caused by sustained factors, are key issues associated with groundwater use, and they define the reduction in streamflow rates caused by various factors that are hydraulically related to a given stream. With watershed development and increasing groundwater use, studies evaluating these phenomena have recently gained interest. However, there are many difficulties in investigating continuous stream drying and studying the phenomena from a quantitative perspective. The difficulties come from complex factors that are not clearly understood or defined (Jung \& Kim, 2017) and the lack of hydrological data in small rivers where stream drying usually occurs. Jung, Lee, Lee and Kim (2019) considered stream drying phenomena by applying five different factors, groundwater use, afforestation, watershed development, road development, and soil erosion, and ranked their contribution rates to the loss of runoff. The results demonstrated that increase of groundwater use and forest growth had a relatively higher influence on stream drying than did other factors.

Increased population numbers and increased amounts of harvest trigger increases in water demand. Although the demand can be fulfilled using surface water sources such as lakes, rivers, and reservoirs, heavy rain in South Korea is concentrated in Summer; thus, the water demand in other seasons cannot be met from surface water stored in the sources. Therefore, groundwater is often used solely or with surface water to satisfy insufficient surface water supplies. However, when groundwater use exceeds groundwater recharge for a long time, groundwater depletion can occur (Gleeson et al., 2010), and the lowering of groundwater levels can result in serious effects on natural streamflow and related ecosystems (Kirk \& Herbert, 2002). Many studies have tried to determine the hydrological impacts of groundwater use. Wen and Chen (2006) explored the spatial distribution of streamflow trends for and climatic impacts on the watershed and concentrated on the analysis of streamflow residuals from gauging stations to determine 
the decrease in baseflow caused by groundwater withdrawals. Kim, Lee, Lee and Won (2012) quantified the streamflow depletion from groundwater pumping for the target watershed. Jung and Kim (2017) identified stream drying by tracing the flow decrease from cell-based hydrological routing under different land use and groundwater use conditions. controlling the rate of evapotranspiration, and extracting groundwater from vegetation roots. Thus, quantifying the influences of forest growth on watershed hydrology is crucial for planning forest or land management and adaptation strategies for watershed ecosystem sustainability. The relationship between forest growth and water cycle in watersheds has been studied for a long time, and several studies have demonstrated that forest changes can significantly affect streamflow and watershed hydrology by altering its pattern, magnitude, frequency, and quality. Mackay and Band (1997) showed that the canopy distribution has significant effects on simulated hydrological outputs where evaporative demand exceeds available water. Birkinshaw, Bathurst, and Robinson (2014) made full use of the unique 45year dataset over the entire cycle from the original upland grassland vegetation through plowing the catchment and through forest growth up to mature trees. The results showed clear changes in the nonstationary nature of the catchment, with an annual increase in intercepted evaporation and a decrease in discharge as the trees grew. Yue and Hashino (2004) assessed the impact of forest growth on the streamflow of the basin using statistical trend analysis. The results demonstrated that forest growth was responsible for the decrease in all regimes and that the increase in evapotranspiration due to forest growth resulted in a decrease in both total runoff and low flow.

This study applied the periodic changes of groundwater use and forest growth to the hydrological model and quantified their influences on watershed hydrology. It is believed that considering the two effective stream drying factors and defining their relative contributions to 
watershed hydrology will improve previous studies that did not consider them together. The study was performed using the Soil and Water Assessment Tool (SWAT), and the applicability of SWAT in simulating watershed scale hydrology and water quality has been proven around the world (Shi et al., 2011; Zhang, Srinivasan, Arnold, Izaurralde \& Bosch, 2011; Luo, Arnold, Allen \& Chen, 2012; Lee, Shin \& Jung, 2014; Lee, Jung, Kim \& Kim, 2019; Woo, Jung, Lee \& Kim, 2019). SWAT was calibrated to verify its applicability in simulating the watershed hydrology of the Geum River basin. The calibrated SWAT simulated the watershed hydrology under three scenarios, and the results were analyzed to determine the contributions of water loss factors to the hydrologic variations.

\section{DATA AND METHODS}

\subsection{Study Area}

The Geum River is one of the four national and major rivers in South Korea, located in the Midwest part of the country with a basin area of $9,912 \mathrm{~km}^{2}$ and a river length of $397.79 \mathrm{~km}$. The rivers in South Korea are generally classified into three groups: rivers of state, local level 1, and local level 2. Currently, there are 11 rivers of state with a total of $397.79 \mathrm{~km}, 20$ rivers of local level 1 with a total of $358.70 \mathrm{~km}$, and 460 rivers of local level 2 with a total of 3000.87 $\mathrm{km}$ in the Geum River basin. However, among 460 rivers of local revel 2, 39 rivers are experiencing stream drying phenomena and their total length is $25 \mathrm{~km}$ (Korea Water Resources Corporation, 2009).

The Geum River originates from southwestern South Korea, where Yongdam Dam (YDD) is located. It passes through Daecheong Dam (DCD), Sejong Weir (SJW), Gongju Weir (GJW) and Baekjae Weir (BJW) and discharges into the West Sea. The five hydraulic structures support five million people living in the region and are crucial since most hydrologic inflows arriving during the flood season are stored in the facilities and used throughout the dry season. 
Furthermore, two TDR (Time Domain Reflectometry) points and one flux tower named Gyebuk (GB), Cheoncheon (CC), and Dyeoku (DU) are located at YDD watershed (Figure 1). The dominant soil textures of the study are sandy loam and loam which occupies $58 \%$ and $24 \%$. The predominant land use in the basin is forest that accounts for $62 \%\left(5,980 \mathrm{~km}^{2}\right)$. Cultivated cropland, composed of paddy fields and upland crops, is mainly distributed in lowland fertile areas covering $26 \%\left(2,508 \mathrm{~km}^{2}\right)$. The remaining areas are filled with urban, grassland, and bare fields that each cover $3-5 \%$ of the whole catchment.

\section{[Insert Figure 1]}

\subsection{Soil and Water Assessment Tool (SWAT)}

SWAT is a watershed hydrology model developed to quantify the impact of land management practices. The model operates by dividing the watershed into subbasins, with each subbasins being connected to stream channels. Subbasins are further divided into hydrological response units (HRUs), which are portions of a subbasin that possess unique land use, management, and soil attributes. The simulation of the hydrological cycle is based on the water balance equation:

$$
S W_{t}=S W_{0}+\sum_{i=1}^{t}\left(R_{d a y}-Q_{\text {surf }}-E_{a}-W_{\text {seep }}-Q_{q w}\right)_{i}
$$

The water balance for dams or floodgates considers inflow, outflow, precipitation, evapotranspiration, and seepage. The equation is expressed as follows:

$$
V=V_{\text {stored }}+V_{\text {flow in }}-V_{\text {flow out }}+V_{\text {pcp }}-V_{\text {evap }}-V_{\text {seep }}
$$

where $V$ is the water storage in the reservoir at the end of each day; $V_{\text {stored }}$ is the volume of water stored in the reservoir at the beginning of a day; $V_{\text {flow }}$ in and $V_{\text {flow out }}$ are the volumes of water entering and flowing out of the reservoir throughout a day, respectively; and $V_{p c p}, V_{\text {evap }}$, and $V_{\text {seep }}$ 
are the volumes of precipitation falling into the reservoir, the water removed by evaporation and the water lost by seepage, respectively.

\subsubsection{Groundwater Use Increase}

Consumptive water use is a management tool in SWAT that removes water from a basin. Water removed for consumptive use is designed to be lost from the system. The removal can be applied from month to month in a subbasin unit. For each month in the year, an average daily volume of water is removed from the source and is specified (Neitsch, Arnold, Kiniry \& Williams, 2005). A shallow aquifer composed of sand, gravel, and clay is distributed throughout South Korea. The aquifer has good porosity with adequate nutrients for cultivation so that it is mainly used as a major source of groundwater (Park, Lee, Koo \& Kim, 2016). Thus, monthly groundwater use was applied to be removed from a shallow aquifer using consumptive water use tool in SWAT.

The National Groundwater Information Center updates annual groundwater use report which provides groundwater use information in three types: agricultural, industrial, and domestic. Based on the report, the annual use data in study area from 1976 to 2015 were collected and they were monthly averaged in 10-year periods (1980s;1976 1985, 1990s; 1986 1995, 2000s; 1996 2005, 2010s;2006 2015) so that SWAT could simulate groundwater use increase scenario periodically. However, the groundwater use data obtained from the report were provided in the unit of administrative district. Thus, the data were recalculated into subbasin unit using areal average method and used as an unput data of SWAT. Figure 2 illustrated the annual use of groundwater use in the study area corresponding to the four decades. The groundwater use showed temporal increase with the value of $221.810^{6}$ ton, $263.210^{6}$ ton, $355.310^{6}$ ton, and 460.5 $10^{6}$ ton in the 1980 s, 1990s, 2000s, and 2010s, respectively. The groundwater use increase (GI) was applied to SWAT by means of investigating temporal and spatial impact of GI on the study area. 
[Insert Figure 2]

\subsubsection{Forest Growth}

In the initial period of plant growth, canopy height and leaf area development are controlled by the optimal leaf area development curve:

$$
f r_{L A I m x}=\frac{f r_{P H U}}{f r_{P H U}+\exp \left(l_{1}-l_{2} \cdot f r_{P H U}\right)}
$$

where $f r_{\text {LAImx }}$ is the fraction of the plant's maximum leaf area index (LAI) corresponding to a given fraction of potential heat units for the plant, $f r_{P H U}$ is the fraction of potential heat units accumulated for the plant on a given day in the growing season, and $l_{1}$ and $l_{2}$ are shape coefficients.

The shape coefficients are calculated by solving Equation 4 and 5 using two known points 169

$$
\begin{aligned}
& \left(f r_{L A I, 1}, f r_{P H U, 1}\right) \text { and }\left(f r_{L A I, 2}, f r_{P H U, 2}\right): \\
& l_{1}=\ln \left[\frac{f r_{P H U, 1}}{f r_{L A I, 1}}-f r_{P H U, 1}\right]+l_{2} \cdot f r_{P H U, 1} \\
& l_{2}=\frac{\left(\ln \left[\frac{f r_{P H U, 1}}{f r_{L A I, 1}}-f r_{P H U, 1}\right]-\ln \left[\frac{f r_{P H U, 2}}{f r_{L A I, 2}}-f r_{P H U, 2}\right]\right)}{f r_{P H U, 2}-f r_{P H U, 1}}
\end{aligned}
$$

where $l_{1}$ is the first shape coefficient, $l_{2}$ is the second shape coefficient, $f r_{P H U, 1}$ is the fraction of the growing season corresponding to the $1^{\text {st }}$ point on the optimal leaf area development curve, $f r_{L A I, 1}$ is the fraction of the maximum plant LAI corresponding to the $1^{\text {st }}$ point on the optimal leaf area development curve, $f r_{P H U, 2}$ is the fraction of the growing season corresponding to the $2^{\text {nd }}$ point on the optimal leaf area development curve, and $f r_{L A I, 2}$ is the fraction of the maximum plant LAI corresponding to the $2^{\text {nd }}$ point on the optimal leaf area development curve. 
For tree stands, the canopy height varies from year to year rather than from day to day:

$$
h_{c}=h_{c, \max } \cdot\left(\frac{y r_{\text {cur }}}{y r_{\text {fulldev }}}\right)
$$

where $h_{c}$ is the canopy height for a given day $(\mathrm{m}), h_{c, \max }$ is the plant's maximum canopy height (m), $y r_{\text {cur }}$ is the age of the tress (years), and $y r_{\text {fulldev }}$ is the number of years for the tree species to reach full development (years). Once plant growth reaches the maximum canopy height, $h_{c}$ remains the same until the plant is killed. However, the kill operation of tree is not activated in the model, and forest height will maintain its maximum value when forest growth stops (Neitsch et al., 2005).

Forest height and LAI were used to represent decadal forest growth condition in this study. Decadal forest height information was collected from forest type maps of Korea Forest Service that include various forest related data including forest height, forest type, diameter of breast height, and so on. LAI data were retrieved from the Land Processes Distributed Active Archive Center (LP DAAC) which supports monthly LAI (MOD15A2) measured at a 1,000 m spatial resolution. However, the retrieval has the limitation that the measurement has started from year of 2000. Thus, LAI data from 1976 to 1999 were regressed using the relationship between forest height and LAI. The regression was done applying power function which showed the most appropriate curve fitting between forest height and LAI (Yongwei, Xinsheng, Fang \& Jinyan, 2013). Collected forest information were then averaged and divided into a 10-year interval which are coincident with the interval used for GI database. The average value of forest height showed the value of $4.4 \mathrm{~m}, 6.3 \mathrm{~m}, 8.5 \mathrm{~m}$, and $9.9 \mathrm{~m}$ in the 1980s, 1990s, 2000s, and 2010s, respectively. The value of LAI showed the value of $0.7,1.5,2.7,3.7$ in the 1980s, 1990s, 2000s, and 2010s, respectively.

The leaf area development curve (Figure 3. (a)) and canopy height development curve (Figure 3. (b)) are determined by six parameters, two known points on the optimal leaf area development 
curve $\left(f r_{L A I}, f r_{P H U}\right)$, the maximum LAI (BLAI), the fraction of the growing season at which senescence becomes the dominant growth process (DLAI), the maximum canopy height (CHTMX), and the number of years for the tree species to reach full development $\left(y r_{\text {fulldev }}\right)$. Since averaged values were retrieved and applied to SWAT, leaf area and canopy height development curves were devised by fitting the six parameters to maintain the LAI and canopy height at their periodic averages while simulating the watershed hydrology (Figure 3).

\section{[Insert Figure 3]}

\section{RESULTS}

\subsection{SWAT Calibration}

SWAT was calibrated to verify its applicability of simulating the watershed hydrology of the Geum River basin. Three hydrologic factors including evapotranspiration, soil moisture, and streamflow were calibrated using observed data and simulated result in daily time steps. The monitoring points are one flux tower (DU) for evapotranspiration, two TDR (Time Domain Reflectometry) points (CC, GB) for soil moisture, and five hydraulic structures including two multipurpose dams (YDD, DCD) and three multifunction weirs (SJW, GJW, BJW) for streamflow. While 4 years (2002 2005) were used as a warm-up period, the calibration was performed from 2006 to 2015 . The calibration period for each component was settled based on the operation period and the quality of observation data which led to the year of 2006 2015 for streamflow at multipurpose dams, 2012 2015 for streamflow at multifunction weirs, 2011 2015 for evapotranspiration, and 2014 for soil moisture.

SWAT parameters adjusted to calibrate the model are the SCS curve number, Manning `s " $n$ " value, soil evaporation compensation factor, groundwater delay time, threshold depth for the return flow in the shallow aquifer, baseflow recession constant, saturated hydraulic conductivity, 
snowfall temperature, snow melt base temperature, and hydraulic structure sources (Table 1).

Default value was used for other parameters that are not mentioned in Table 1.

227

The model performance for streamflow was evaluated by coefficient of determination $\left(\mathrm{R}^{2}\right)$, Nash-Sutcliffe efficiency (NSE), root mean square error (RMSE), and percent bias (PBIAS).

The calibration at two dams and three weirs achieved the average $\mathrm{R}^{2}$ value of $0.73,0.82,0.79$, $0.81,0.82$, NSE value of $0.81,0.77,0.75,0.75,0.77$, RMSE value of $2.35 \mathrm{~mm} /$ day, 1.57 $\mathrm{mm} /$ day, $0.53 \mathrm{~mm} /$ day, $0.54 \mathrm{~mm} /$ day, $0.58 \mathrm{~mm} /$ day, and PBIAS value of $-2.51,-8.44,+3.2$, $+11.74,+10.73 \%$ for YDD, DCD, SJW, GJW, and BJW, respectively. Table 2 presented the statistical summary of streamflow calibration at five monitoring points. On the other hand, the model performance for evapotranspiration and soil moisture was evaluated by coefficient of determination $\left(\mathrm{R}^{2}\right)$. The calibration result of evapotranspiration and soil moisture achieved average $\mathrm{R}^{2}$ value of 0.45 and 0.44 , respectively. Graphical comparison of streamflow, evapotranspiration, and soil moisture between observed data and calibrated result is shown in Figure 4.

[Insert Table 1]

[Insert Table 2]

242

[Insert Figure 4]

\subsection{Hydrologic Responses}

245 Calibrated model ran 10-year hydrology of the target watershed. The decadal watershed hydrology was explained by hydrological components including evapotranspiration (ET), surface runoff (SR), percolation (PE), soil moisture (SM), groundwater flow (GF), infiltration (IN), groundwater recharge (GWR), and lateral flow (LF). 
The watershed hydrology of the 1980s using corresponding GI and FG condition was used as a standard to estimate hydrologic response caused by the two factors. Three scenarios were applied to understand how GI and FG separately and concurrently affected watershed hydrology. GI scenario considered decadal change of groundwater use increase, FG scenario reflected decadal change of forest condition, and stream drying (SD) scenario simulated decadal groundwater use increase and forest growth simultaneously. When considering three scenarios, the periodic condition of groundwater use and forest condition corresponding to each decade was applied to SWAT while weather condition was fixed to the 2010s so that the impact of GI and FG on watershed hydrology can be observed.

\subsubsection{Hydrologic Responses to Groundwater Use Increase}

The increase of groundwater use has temporally decreased GF and increased GWR. Groundwater flow showed the decrease of 5.6\% (5.0 mm/year), $16.2 \%$ (15.4 mm/year), and $15.2 \%(24.9 \mathrm{~mm} / \mathrm{year})$ in the $1990 \mathrm{~s}, 2000 \mathrm{~s}$, and $2010 \mathrm{~s}$, respectively. Groundwater recharge showed the increase of $1.7 \%$ (5.0 $\mathrm{mm} /$ year $), 0.5 \%$ ( $15.4 \mathrm{~mm} /$ year $)$, and $10.4 \%$ (24.9 $\mathrm{mm} /$ year $)$ in the 1990s, 2000s, and 2010s, respectively. Resultingly, total runoff (TR) has temporally decreased and showed the decrease percentage of $0.9 \%(7.0 \mathrm{~mm} /$ year $), 3.1 \%(24.1 \mathrm{~mm} /$ year $)$, and $5.8 \%$ (44.9 mm/year) in the 1990s, 2000s, and 2010s, respectively (Table 3).

[Insert Table 3]

Spatially, the decrease of total runoff in three periods against the 1980s was estimated in subbasin unit (Figure 5). The vulnerability of total runoff decrease was relatively higher in the Midwest and Northern part of the study area. The maximum decrease percentage was appeared to be $3.0 \%(16.0 \mathrm{~mm} /$ year $), 8.2 \%(50.2 \mathrm{~mm} /$ year $)$, and $12.2 \%(88.9 \mathrm{~mm} /$ year $)$ in the $1990 \mathrm{~s}$, 
2000s, and 2010s, respectively.

275

276

[Insert Figure 5]

277

278

\subsubsection{Hydrologic Responses to Forest Growth}

279

Decadal growth of forest has temporally increased ET with the value of $0.5 \%$ ( $2.9 \mathrm{~mm} / \mathrm{year}), 1.5 \%$

280

(8.6 mm/year), $2.4 \%(13.4 \mathrm{~mm} /$ year) in the $1990 \mathrm{~s}, 2000 \mathrm{~s}$ and $2010 \mathrm{~s}$, respectively. The increased

281

282

283 $\mathrm{mm} /$ year), and $2.0 \%$ (15.8 mm/year) in the 1990s, 2000s and 2010s, respectively (Table 4).

284

285

[Insert Table 4]

286 in the 1990s, 2000s, and 2010s, respectively.

291

292

[Insert Figure 6]

293

294

295

296 trend of SR, PE, SM, GF, and LF while ET and GWR showed increasing trend. Consequently, TR was decreased by $1.3 \%$ (10.1 mm/year), $4.4 \%$ (34.2 mm/year), and 7.8\% (60.3 mm/year) in the 1990s, the 2000s, and the 2010s, respectively (Table 5). 
[Insert Table 5]

301

In SD scenario, the spatial vulnerabilities in groundwater use increase and forest growth scenario were integrated and showed that the subbasins vulnerable to TR loss were prevalent along the downstream and West-Northern part of the target watershed (Figure 7). The maximum decrease percentage showed the value of $3.6 \%$ (24.7 mm/year), $10.3 \%(74.1 \mathrm{~mm} /$ year $)$ and $14.9 \%$ (116.9 mm/year) in the 1990s, 2000s and 2010s, respectively.

[Insert Figure 7]

\subsection{Flow-duration curve}

The flow-duration curve at the watershed outlet in each decade was analyzed to understand the impact of stream drying factors on the annual streamflow. Using the descending order of streamflow data, the flow rate corresponding to the time duration of $95,185,275,355$ day was extracted for each scenario. The time duration of 95, 185, 275 and 355 stands for wet season, normal season, dry season, and drought season that are frequently used to represent the annual condition of streamflow in South Korea.

Figure 8 showed the reduction rate of streamflow in three scenarios with four different time durations compared with the rate in the 1980s. There are two noticeable trends observed from the result. First, the reduction rate has temporally increased in all scenarios. The rate of the 1990s, $2000 \mathrm{~s}$, and $2010 \mathrm{~s}$ showed the value of $3.1 \%, 8.2 \%$, and $13.2 \%$ in Q355 groundwater use increase scenario, $2.3 \%, 3.3 \%$, and $3.9 \%$ in Q355 forest growth scenario, $4.3 \%, 10.6 \%$, and $16.8 \%$ in Q355 stream drying scenario, respectively. These increasing trends appeared same in every time duration. Secondly, the streamflow in bigger duration showed higher value of reduction rate. The 
reduction rate of Q95, Q185, Q275, and Q355 showed the value of 5.6\%, 6.6\%, 8.1\%, and 13.2\% in the 2010 s groundwater use increase scenario, $1.8 \%, 1.9 \%, 2.1 \%$, and $3.9 \%$ in the 2010 s forest growth scenario, $7.3 \%, 8.3 \%, 9.5 \%$, and $16.8 \%$ in the 2010 s stream drying scenario, respectively. The increasing pattern has also appeared same in every decade.

[Insert Figure 8]

\section{DISCUSSION}

The long-term change of GI and FG has clearly affected the watershed hydrology and water cycle of the target watershed which resultingly caused spatial and temporal decrease of TR and streamflow. By the way, the two factors showed different way of influence on the watershed hydrology and water cycle. Decadal increase of groundwater use has temporally decreased GF and increased GWR while other hydrological components were not affected. The increasing groundwater use has lowered groundwater level and forced overlying saturated zone to fill up the deficit which successively decreased GF and increased GWR. In the aspect of FG, the increase of ET, a natural result of the vegetation growth, was the initial point of hydrologic response. The increased ET triggered the decrease of SR and the mass of water infiltrated into the soil layer. Lessened infiltration then reduced the underground components including LF, PE, FG, and GWR. These series of hydrologic response imposed by decadal GI and FG consequently decreased TR and streamflow in the target watershed.

The spatial vulnerability of TR loss in GI and FG scenario showed different distribution in study area. The vulnerability in GI scenario followed the increment of groundwater use while one in FG scenario fitted well with the distribution of forested area proving that the model simulation made a good agreement with the spatial change of groundwater use increase and forest growth. By the way, the spatial vulnerability of TR loss influenced by groundwater use increase 
and forest growth was more vulnerable in the subbasins with smaller stream order which explained that small streams are relatively vulnerable to stream drying.

The analysis on decadal flow-duration curve suggested two noticeable trends. One is the temporal decrease of streamflow that noticed the decadal GI and FG has consistently worsened the annual streamflow condition. Another trend was related to the flow rate in different time duration. The flow rate in the bigger time duration showed higher value of reduction rate in every scenario. This can indicate that the influence of decadal GI and FG on the streamflow loss becomes stronger in the condition of lower flow rate.

Monthly analysis on hydrologic responses explained the relationship between the climate characteristic of South Korea and the hydrologic response. The hydrologic components in the 2010s SD scenario were compared with the 1980s SD scenario. The change rates of hydrological components in month are presented in Table 6 . The response of every hydrologic component showed relatively higher value in June and July. It is due to the climate characteristic of South Korea that shows concentrated rainfall in Summer. Because of the concentration, the tendency to increase from January to June and decrease from June to December was observed from monthly hydrologic response while GF had additional tendency that the reduction rate increases from October to December and decreases from December to May. The cultivation, one of the farming methods for dry period, uses pumped groundwater to reserve water supply during dry period and keep vinyl house warm. Regarding that water curtain cultivation is usually performed from October to March throughout South Korea, and its development has been largely expanded for the past four decades (Chung and Chang, 2016), the additional trend can be explained by water curtain cultivation.

\section{[Insert Table 6]}




\section{CONCLUSIONS}

375 The long-term GI and FG impact on the watershed hydrology was evaluated using SWAT. Based on the groundwater use and forest growth database from 1976 to 2015, decadal change of groundwater use and forest growth was prepared for 10-year interval (1980s;1976 1985, 1990s; 1986 1995, 2000s; 1996 2005, 2010s;2006 2015). SWAT was calibrated based on the observed data of evapotranspiration, soil moisture, and inflow data at monitoring points. The calibrated model estimated watershed hydrology of three scenarios in terms of hydrological components. The hydrological response to groundwater use increase and forest growth was then measured comparing decadal results. of both GI and FG has been considered, TR in the study area has temporally decreased and showed the reduction rate of $3.6 \%, 10.3 \%$, and $14.9 \%$ in the $1990 \mathrm{~s}, 2000 \mathrm{~s}, 2010 \mathrm{~s}$, respectively. result showed that they have clear impact on the water cycle and the decrease of streamflow. However, there are still more factors that are expected to affect watershed hydrology which are land use change, road network development, and soil erosion. These factors have also temporally 
399 developed and should be considered in the further studies so that we can figure out 400 comprehensive impact of stream drying factors on watershed hydrology and prepare water 401 resource management.

402

403 FUNDING

404 This paper was funded by Konkuk University in 2017

405

406

407

ACKNOWLEDGEMENTS

408

409

AUTHORS CONTRIBUTION

410

Wonjin Kim: Conceptualization, Methodology, Writing-Original Draft Preparation, Seongjoon

411 Kim: Supervision, Editing, Jinuk Kim: Visualization, Jiwan Lee: Investigation. Soyoung Woo:

412 Data Curation, Sehoon Kim: Validation.

413

414 ETHICAL APPROVAL

415 Not applicable, because this article does not contain any studies with human or animal subjects

416

417 CONSENT TO PARTICIPATE

418 Informed consent was obtained from all individual participants included in the study. 
421 All the authors give the Publisher the permission of the authors to publish the research work.

\section{CONFLICTS OF INTEREST}

424 The authors have no conflicts of interest to declare.

425

\section{DATA AVAILABILITY}

427

The data and materials that support the findings of this study are available on request from the corresponding author.

\section{REFERENCES}

431

432

433

434

435

436

437

438

439

440

441

442

443

Birkinshaw, S.J., Bathurst, J.C. \& Robinson, M. (2014). 45 years of non-stationary hydrology over a forest plantation growth cycle, Coalburn catchment, Northern England. Journal of Hydrology. 519, 559-573.

Chung, I.M. \& Chang, S.W. (2016). Analysis and evaluation of hydrological components in a water curtain cultivation site. Journal of Korea Water Resoure Association. 49(9), $731-740$.

Gleeson, T., VanderSteen, J., Sophocleous, M.A., Taniguchi, M., Alley, W.M., Allen, D.M. \& Zhou, Y. (2010). Groundwater sustainability strategies. Nature Geoscience. 3, 378379.

Jung, C.G., Lee, J., Lee, Y. \& Kim, S. (2019). Quantification of stream drying phenomena using grid-based hydrological modeling via long-term data mining throughout South Korea including ungauged areas. Water. 11(3), 477.

Jung, C.G. \& Kim, S.J. (2017). Evaluation of land use change and groundwater use impact on stream drying phenomena using a grid-based continuous hydrologic model. Paddy 
Water Environment. 15(1), 111-122.

Kim, N.W., Lee, J., Lee, J.E. \& Won, Y.S. (2012). Development of relational formula between groundwater pumping rate and streamflow depletion. Journal of Korea Water Resource Association. 45(12), 1243-1258.

Kirk, S. \& Herbert, A.W. (2002). Assessing the impact of groundwater abstractions on river flows. Geological Society, London, Special Publications. 193(1), 211-233.

Lee, G., Shin, Y. \& Jung, Y. (2014). Development of web-based RECESS model for estimating baseflow using SWAT. Sustainability 6(4), 2357-2378.

Lee, J., Jung, C., Kim, S. \& Kim, S. (2019). Assessment of climate change impact on future groundwater-level behavior using SWAT groundwater-consumption function in Geum river basin of South Korea. Water. 11(5), 949.

Luo, Y., Arnold, J., Allen, P. \& Chen, X. (2012). Baseflow simulation using SWAT model in an inland river basin in Tianshan mountains, Northwest China. Hydrology and Eart System Sciences. 16(4), 1259-1267.

Mackay, D.S. \& Band, L.E. (1997). Forest ecosystem processes at the watershed scale: dynamic coupling of distributed hydrology and canopy growth. Hydrological Processes. 11(9), 1197-1217.

Neitsch, S.L., Arnold, J.G., Kiniry, J.R. \& Williams, J.R. (2005). Soil and Water Assessment Tool Theoretical Documentation. Version 2005. Springer, Berlin.

Park, G., Lee, H., Koo, M.H. \& Kim, Y. (2016). Strategies for an effective artificial recharge in alluvial stream-aquifer systems undergoing heavy seasonal pumping. Journal of the Geological Society of Korea. 52(3), 211-219.

Shi, P., Chen, C., Srinivasan, R., Zhang, X., Cai, T., Fang, X., ..., Li, Q. (2011). Evaluating the SWAT model for hydrological modeling in the Xixian watershed and a comparison with the XAJ model. Water Resources Management. 25(10), 2595-2612. 
470 Wen, F. \& Chen, X. (2006). Evaluation of the impact of groundwater irrigation on streamflow in Nebraska. Journal of Hydrology. 327(3-4), 603-617.

Zhang, X., Srinivasan, R., Arnold, J., Izaurralde, R.C. \& Bosch, D. (2011). Simultaneous

Woo, S.Y., Jung, C.G., Lee, J.W. \& Kim, S.J. (2019). Evaluation of watershed scale aquatic ecosystem health by SWAT modeling and random forest technique. Sustainability. 11(12), 3397.

Yongwei, Y., Winsheng, W., Fang, Y. \& Jinyan, Z. (2013). Examination of the Quantitative Relationship between Vegetation Canopy Height and LAI. Advances in Meteorology.

Yue, S. \& Hashino, M. (2004). Statistical interpretation of the impact of forest growth on streamflow of the Sameura basin, Japan. Environmental monitoring and assessment. 104(1), 369-384. calibration of surface flow and baseflow simulations: a revisit of the SWAT model calibration framework. Hydrological Processes. 25(14), 2313-2320. 


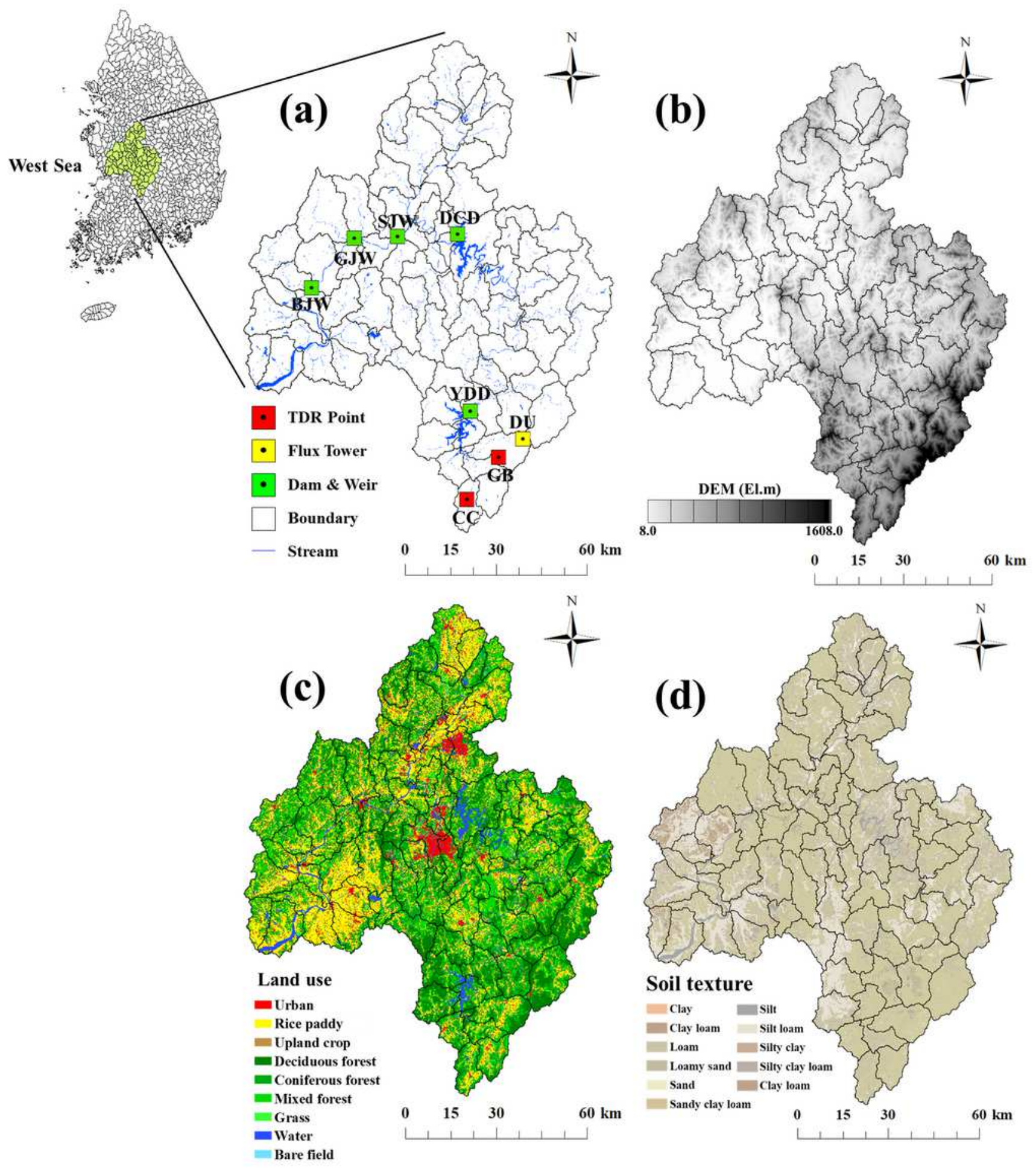

\section{Figure 1}

Spatial information of the study area including (a) monitoring points, (b) digital elevation map, (c) land use, and (d) soil texture. 

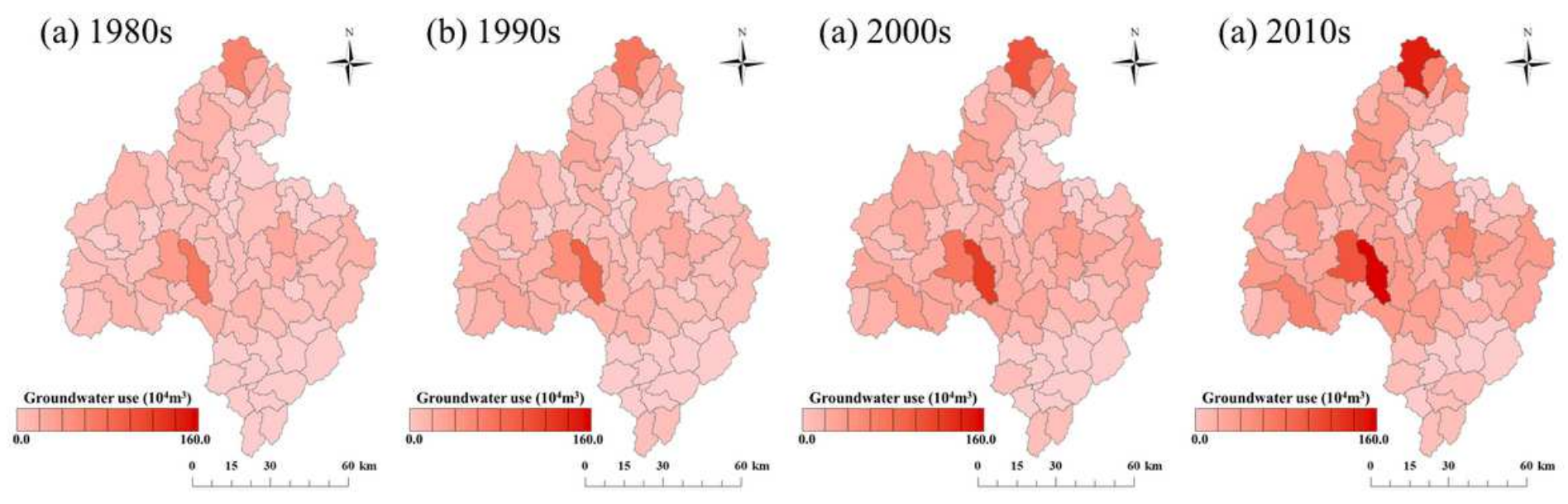

Figure 2

The annual use of groundwater in the study area corresponding to the four decades.
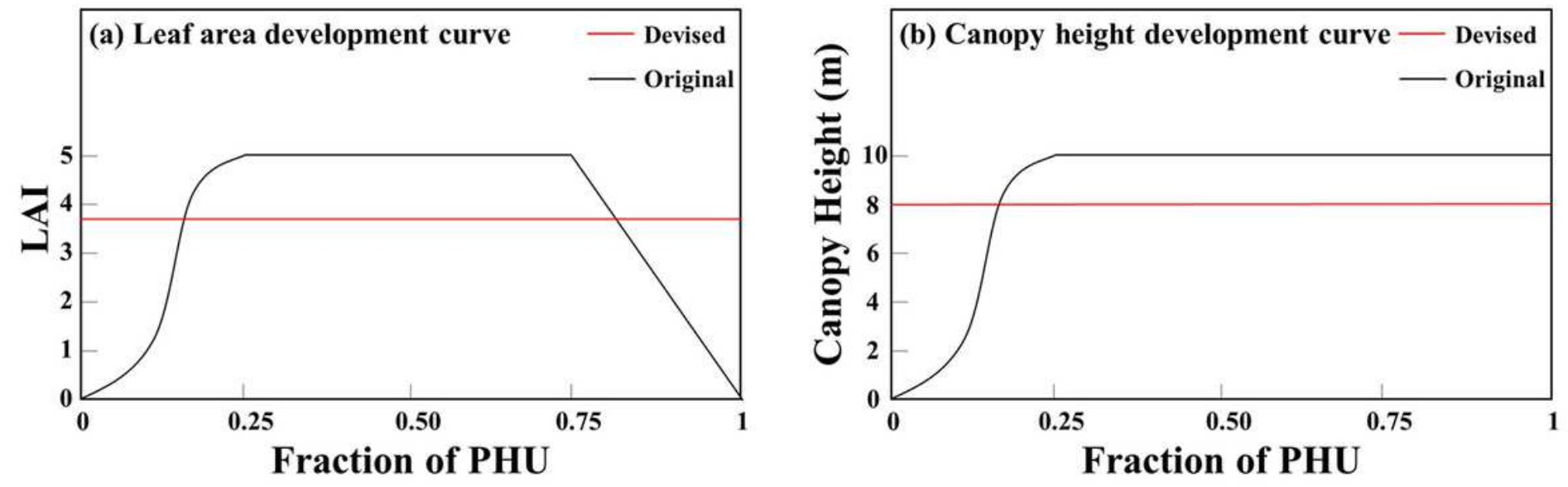

Figure 3

The visualization of the original and devised development curve of (a) LAl and (b) canopy height. 

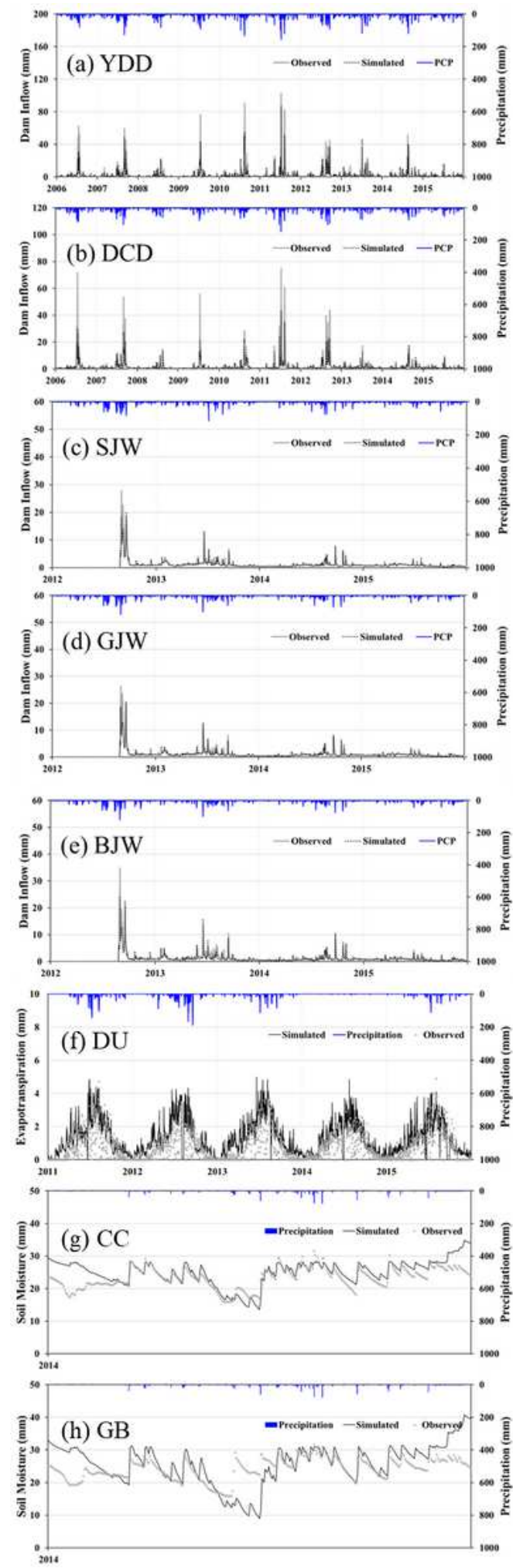

\section{Figure 4}

The graphical comparison between observed and simulated inflow at (a) YDD, (b) DCD, (c) SJW, (d) GJW, and (e) BJW. 

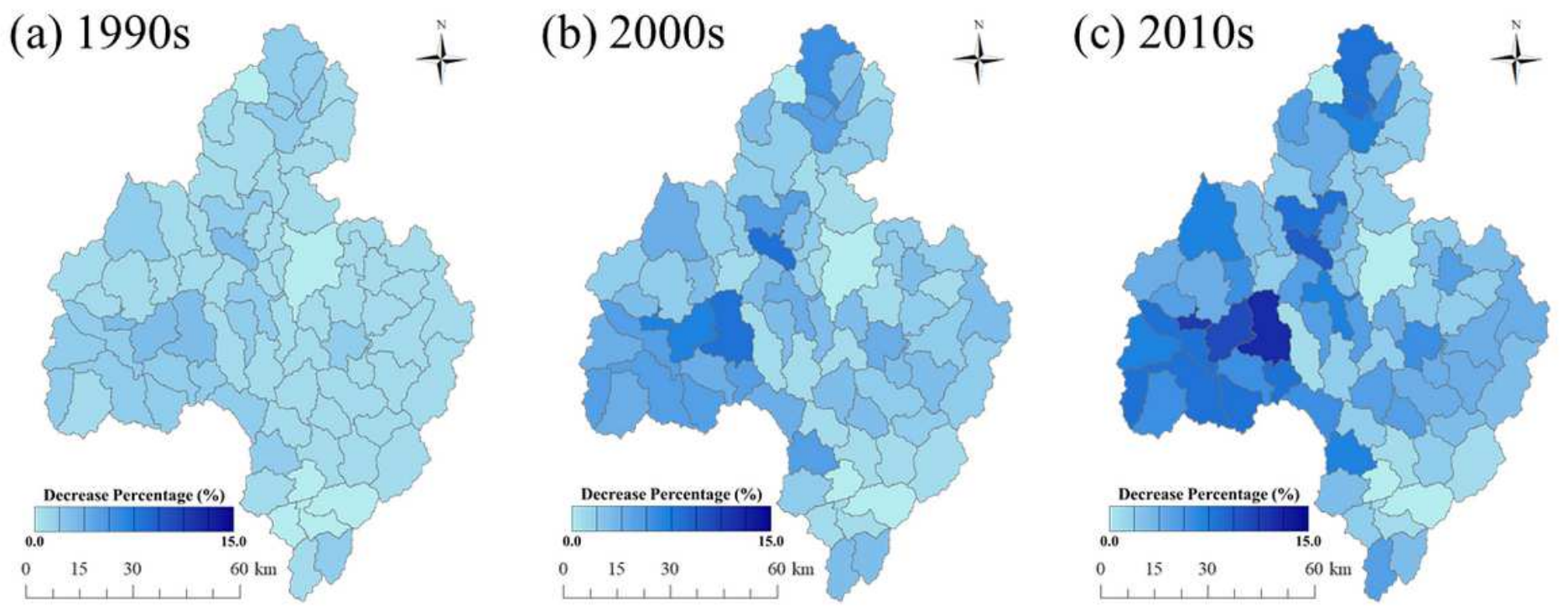

Figure 5

The spatial vulnerability of TR loss caused by groundwater use increase in (a) 1990s, (b) 2000s, and (c) 2010s.
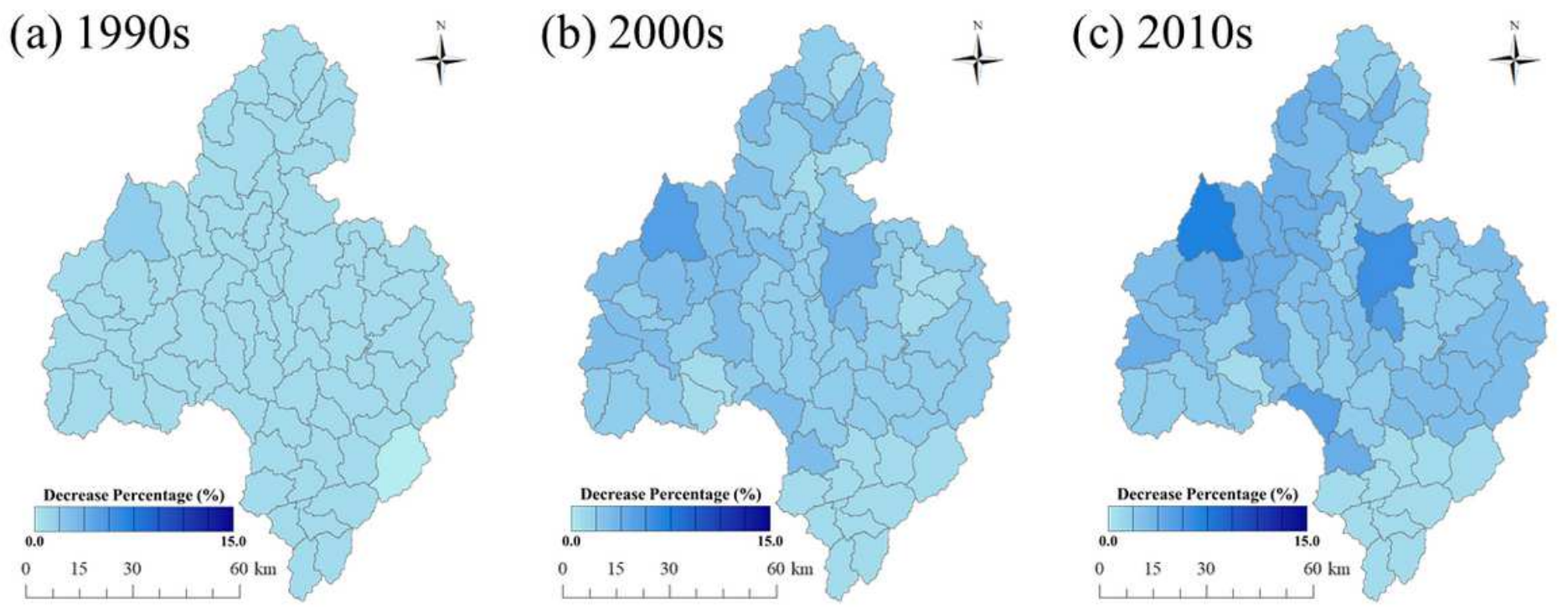

\section{Figure 6}

The spatial vulnerability of TR loss caused by forest growth in (a) 1990s, (b) 2000s, and (c) 2010 s. 
(a) $1990 \mathrm{~s}$

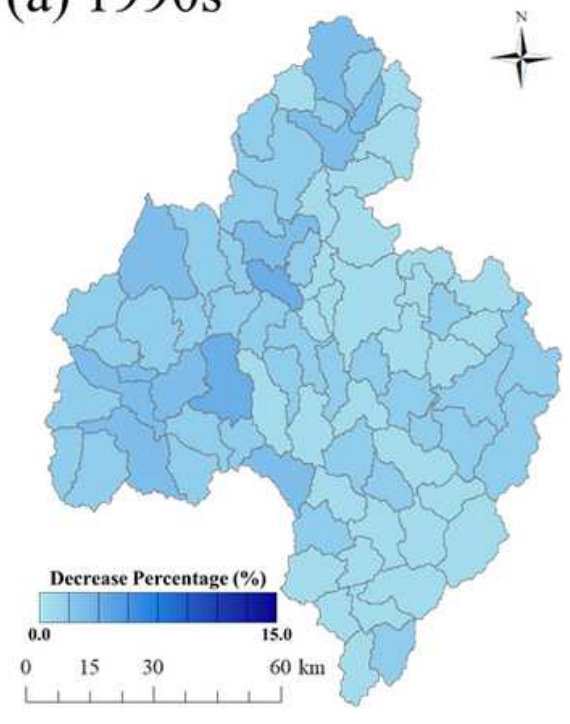

(b) $2000 \mathrm{~s}$

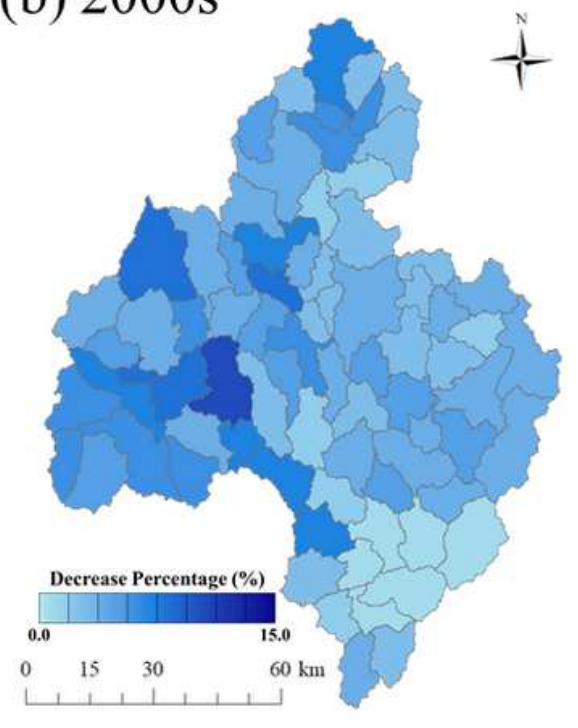

(c) $2010 \mathrm{~s}$

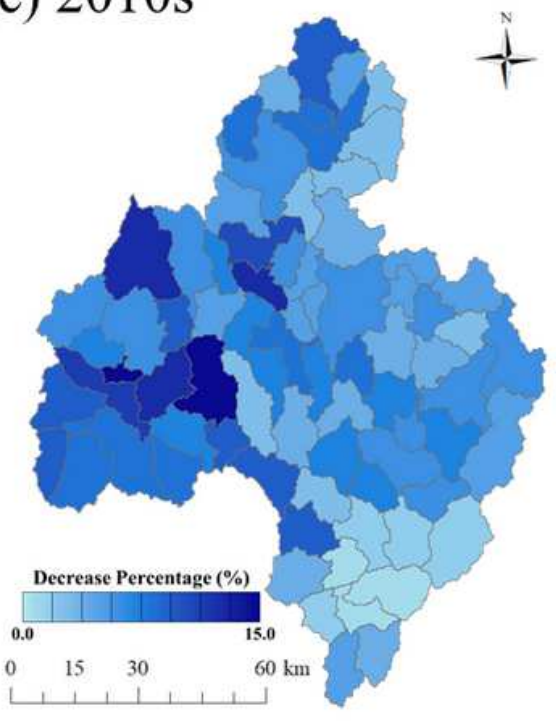

Figure 7

The spatial vulnerability of TR loss caused by groundwater use increase and forest growth in (a) 1990s, (b) 2000s, and (c) 2010s. 
(a) Groundwater use Increase Scenario

1990s $\$ 2000$ s 目2010s
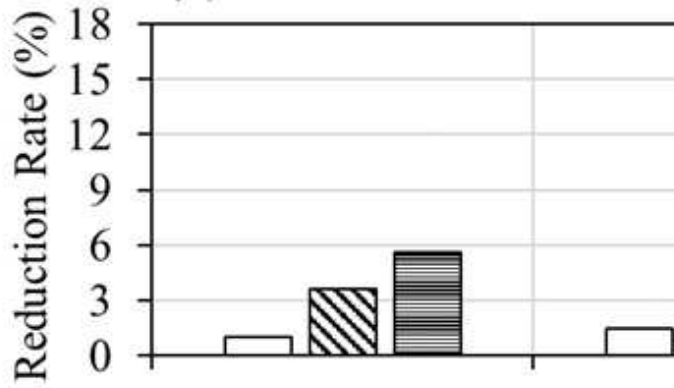

Q95

Q185

Time duration

(b) Forest Growth Scenario

1990s $\$ 2000$ s 目2010s
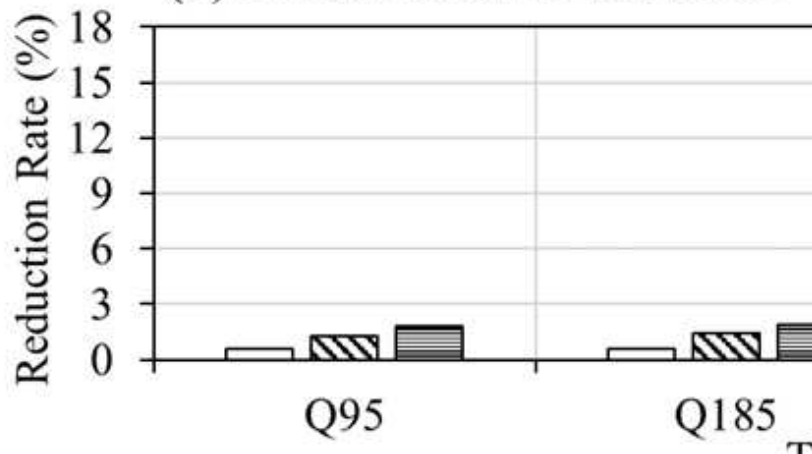

Time duration

(c) Stream Drying Scenario

1990s $\$ 2000$ s
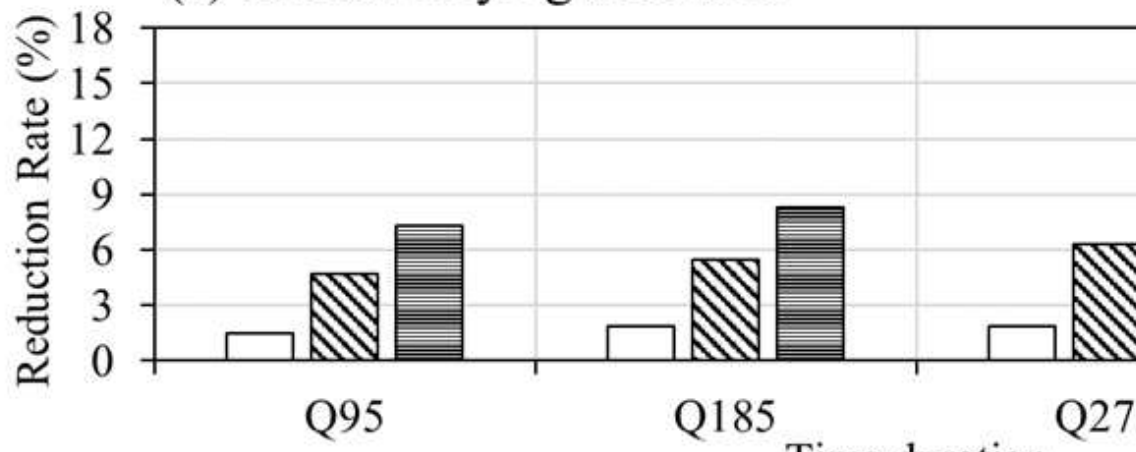

Time duration

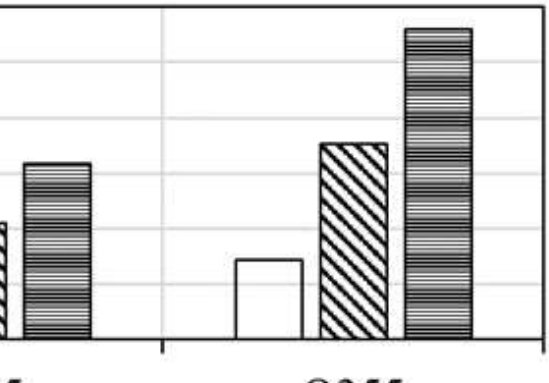

1) Q95 : flow rate corresponding to the time duration of 95

2) Q185 : flow rate corresponding to the time duration of 185

3) Q275 : flow rate corresponding to the time duration of 275

4) Q355 : flow rate corresponding to the time duration of 355

\section{Figure 8}

The temporal reduction rate of streamflow in (a) groundwater use increase scenario, (b) forest growth scenario, and (c) stream drying scenario. 